\title{
AC 2009-1477: DEVELOPING AN INTERNATIONAL STUDY ABROAD PROGRAM THAT IS SUSTAINABLE FROM BOTH FACULTY AND STUDENT PERSPECTIVES
}

\section{E James Nelson, Brigham Young University}

Professor, Civil and Environmental Engineering, Brigham Young University. Teaching and research focus in hydrology and hydrologic modeling

\section{Rollin Hotchkiss, Brigham Young University}

Rollin Hotchkiss teaches hydraulics and stream restoration courses and has a research focus on sedimentation and ecological connectivity in the design of transportation systems

Lourdes Manley, Brigham Young University

Graduate Research Assistant Brigham Young University

\section{Oscar Dzul, Universidad Autonoma de Zacatecas}

Professor of Civil Engineering with a teaching and research focus in hydraulics

Joshua Draper, Brigham Young University

Graduate Research Assistant (2008) Brigham Young University 


\section{Developing an International Study Abroad Program that is Sustainable from Both Faculty and Student Perspectives}

\section{Introduction}

In recent years, more and more industries have recognized the need to work across national and cultural boundaries to be successful ${ }^{1}$. Advances in communications media and the Internet allow instant communication to nearly anywhere on the planet ${ }^{2}$. The net effect has been to shrink the perceived size of the world and significantly reduce the technical difficulties and complexities associated with forming international project teams. Consequently, companies in many industries now face a need to cooperate and work with people from other cultures and value systems in order to remain competitive.

Although many of the physical challenges related to globalization have been overcome, social challenges including communication and cultural, economic, and political differences remain. The skills required to deal with such challenges have generally been overlooked by traditional engineering education, which has focused primarily on teaching the technical skills necessary for students to be successful engineers. Communication, leadership, teamwork, and cultural sensitivity are part of a global skill set that has been identified by the engineering community as necessary for new graduates; therefore, many institutions have modified existing courses or created new ones to develop these skills ${ }^{3}$.

The research presented hereto addresses globalization in the context of civil engineering and has the twofold objective of (1) describing a sustainable engineering study abroad program that could be used as a model to develop the required soft skills for engineers to work in global environments and, (2) describing current and future assessment tools used to measure the success of the program. This ongoing study abroad program is taught in the Civil and Environmental Engineering department at Brigham Young University (BYU) to help students develop the traits of the global engineer.

\section{The Global Engineer}

Engineering educators have realized the impacts of globalization and have already started working to prepare the engineers of the $21^{\text {st }}$ century for a more global industry. Indeed, Jones and Oberst claim that "engineering is probably closer than any other profession to converging worldwide on standards of educational quality." According to the McKinsey Global Institute, engineering ranks as one of the occupations most amenable to outsourcing ${ }^{5}$. Consequently, employers are seeking graduates with experience and an international mindset ${ }^{6}$. They are looking for global engineers to be leaders in a global industry. A global engineer is an engineer who has mastered many of the skills and attributes that have been defined as necessary for an engineer to succeed in the $21^{\text {st }}$ century. Del Vitto ${ }^{7}$ mentions several of these skills and includes "good communication skills (including multiple languages), the ability to work in teams, cross-cultural sensitivity and knowledge, social awareness, capacity to handle complex systems, business acumen and sense of entrepreneurship" as part of the global engineer skill set. 
According to Hederberg, the engineering graduate is a product of his or her university ${ }^{6}$. Therefore, the only way to produce global engineers is within global universities, i.e. universities that emphasize the importance of a global mindset and offer courses designed to equip students with the tools and attributes they need to become global engineers.

Many educational institutions in the United States have developed programs intended to help students develop some or all of the attributes of the global engineer. These programs can generally be classified as either a seminar format or a study abroad format.

\section{Seminar}

The seminar strategy is one wherein the students attend a class that is designed to increase their awareness of other cultures, but does not involve travel. An example of one such class is International Dimensions of Engineering at the University of Illinois, Urbana-Champaign. Guest lecturers from education, business, and industry give an overview of global changes that may place students in foreign countries in their career by sharing their perspective on global changes and how they should prepare for the future ${ }^{10}$.

\section{Study Abroad}

The study abroad strategy involves an agreement between institutions in different geographical locations enabling students to move from one to the other for short or long-term study periods within a single degree program ${ }^{11}$. Parkinson ${ }^{12}$ describes engineering study abroad programs from around the country and groups them into the following categories: Dual Degree, Exchange, Extended Field Trip, Extension, Internship or Co-op, Mentored Travel, Partner Sub-contract, Project Based Learning/Service Learning, and Research Abroad.

\section{Study Abroad Program Challenges}

Despite the importance of study abroad programs, low participation rates have been observed. Only about $3.1 \%$ of engineering students participated in study abroad over the last decade, and for last reported year of $2006 / 07^{13}$. Although many universities recognize the need for engineering study abroad programs, implementing them presents various challenges ${ }^{12}$, such as: Expense: study abroad classes require additional tuition as well as travel expenses. Opportunity cost of internships and time to graduation also increase the effective cost of study abroad.

Faculty Recruitment: it can be difficult to recruit faculty to supervise study abroad programs because they are often diverted from research activities necessary for academic advancement. Furthermore, there is inability to find faculty to teach courses abroad.

Facilities: this is especially true for courses abroad that require a lab; a lack of equipped facilities can be one of the greatest barriers for studying abroad.

Assessment for Accreditation Purposes: engineering programs are required to evaluate how well they meet their objectives. Study abroad programs are difficult to assess and therefore difficult to integrate into an engineering curriculum.

Lack of a Clear Purpose: when study abroad programs fail to specify clear objectives they can end up being mostly project based cooperation between two universities without a clear link to the curriculum. 
Language: only $8 \%$ of students in U.S. universities enroll in language study courses ${ }^{14}$, and far fewer have had an immersion experience in another culture. In order to participate in study abroad programs students must fit foreign language studies into an already heavy schedule. Hard to Scale: exchange and field trip programs often have an upper limit on the number of students who can participate due to resource and staff limitations.

Parental Reluctance: parents may be reluctant for their children to travel to countries with lower standards of health and safety (perceived or real).

Leaving Community of Family and Friends: some students are reluctant to study in an unfamiliar place with different customs.

All of these concerns constitute important practical constraints on program design ${ }^{15}$.

\section{Mexico Engineering Study Abroad (MESA)}

The Mexico Engineering Study Abroad program (MESA) taught at Brigham Young University aims at developing global engineers while minimizing some of the challenges common to study abroad programs. At the Third Workshop on Global Engineering Education, T. Hederberg described a "Renaissance Engineer" 2 and in 2004, the National Academies of Engineering wrote a report in which they describe the characteristics of the engineer of $2020^{8}$. Stemming from this body of research, Draper ${ }^{9}$ defined a comprehensive list of attributes possessed by global engineers that included the key attributes of technical competence, foreign language skills, teamwork, leadership, and cultural sensitivity. These key attributes are mainly what the MESA program focuses to teach and assess in the students that enroll in the study abroad.

The MESA course has its beginnings from internally funded grants that allowed some students to travel to Egypt and Chile to help train civil engineers in the use of water modeling software developed by the Environmental Modeling Research Laboratory (EMRL) at BYU. In March of 2005, a similar trip to Mexico was received with deep interest and led to an ongoing relationship with the University of Zacatecas (UAZ). This partnership has subsequently expanded to include ITESO University in Guadalajara. Because the benefits derived from the grants included the development of global engineering attributes in students that participated, an official study abroad class was established.

As MESA evolved it became apparent that as a study abroad experience it was providing an excellent opportunity for students to learn global engineering while effectively overcoming many of the challenges to traditional programs previously listed. In 2006 the program became an official study abroad program of the university. Its objectives were to help students develop the attributes of the global engineer and to be a sustainable program by being cost-effective and by generating research that could be leveraged both by students and faculty.

As the Civil and Environmental Engineering Department started to place more emphasis on this type of program and MESA was officially adopted by the college of Engineering as a study abroad program, the objectives evolved into the following learning outcomes:

1. Understanding and appreciation for the way engineering is practiced in Mexico.

2. Broader appreciation of how engineers can make a difference in their professional lives.

3. Better understanding of how to apply engineering skills. 
4. More confidence in sharing engineering with others.

5. Make contributions to multi-lingual and multi-cultural teams.

6. Become familiar with the Spanish language in the context of the civil engineering profession.

7. Prepare reports and presentations that can be presented in international settings.

The program is naturally design to achieve these learning outcomes and as the students participate in the study abroad they are exposed to an environment where they can develop technical competence, foreign language skills, teamwork, leadership, and cultural sensitivity.

\section{Class Description}

MESA is a project-based class that couples hydrologic modeling of real projects with international communication and collaboration. It is a hybrid of Parkinson's ${ }^{12}$ research abroad and project-based learning categories and is facilitated by the large number of students at BYU with proficient Spanish language ability. Many of the projects are tied to ongoing research for students at BYU and Mexico. It is taught each winter semester as a three-credit technical elective in the Civil and Environmental Engineering program at BYU. Near the beginning of the semester, professors from partner institutions in Mexico meet with the MESA faculty of BYU to outline candidate projects of Mexican local interest that are either good applications of the hydrologic modeling software developed by the EMRL, or applications stemming from other faculty research specialties. Projects from previous years have included flooding, water quality, hydrologic modeling database development, culvert inventory and design, impact assessment on new dams and other hydraulic structures, and effects on runoff in areas of rapid urban expansion $^{16}$.

Due to the specific technical nature of the projects, students wishing to participate in MESA must have taken an introductory class in hydrology, and must either be concurrently enrolled in a hydrologic modeling class or have Spanish language experience. These two prerequisites empower students to contribute to a team at a high level with either technical or language skills or both. Each project is designed to meet a specific, current need in the community surrounding the partnering university; many of them are part of on-going research, some are sponsored by various levels of government. All are led or mentored by graduate students attending BYU or one of the partnering universities in Mexico.

Once the projects are identified, the students at the partnering universities are divided into teams. At BYU, typically the teams consist of two or three students who are then assigned to work with one of the Mexican student teams on a project. The Mexican teams determine the specific project objectives with input from the BYU teams on applicability. The BYU students help train the Mexicans in the use of the modeling software and together, through electronic communication and various forms of video conferencing, they develop the best solution and discuss strategies for accomplishing it. This is a very important part of the study abroad. Cultural exposure does not necessarily starts when the student travels and lives abroad. As the students work on their projects with their counterparts in Mexico they deal with cultural differences and learn how engineering is practiced in a foreign country, they learn how to make contributions to multi lingual and multi-cultural teams, they learn to reconcile different point of views into one best solution and they sharpen their engineering knowledge and skills as they work to find a solution 
to real-world problems. Near the end of the semester, BYU students travel to Mexico to work alongside their Mexican teammates and ultimately present their results in Spanish to each other, members of the academic community, and other interested parties such as officials from sponsoring government entities.

The MESA class is organized naturally into two main phases: preparation and travel. During the preparation phase, the class meets about once a week for an hour to discuss logistics and class level issues. This includes discussions on teamwork and project management and cultural differences between Mexico and the US. Individual groups meet on their own or with the advising professor as often as necessary to work on their projects. The seemingly lost class time is regained during the travel phase.

\section{Preparation}

One of the first assignments for each group is to prepare a project plan which serves as a contract between themselves and the professor to provide a basis for determining grades. The plan must describe the project objective, specific tasks required to accomplish it, deadlines for each task, and a description of the qualifications and duties of each group member. Along with the project plan, each group is required to document the way they will work together (e.g. assign each member certain tasks based on current abilities or work cooperatively on everything) as well how to handle conflicts when they arise ${ }^{17}$. Each group is expected to submit a weekly memo to document their progress and identify questions and problems. The memos and the project plan are posted to a website created and maintained by the students so that everyone involved, including those in Mexico, can stay informed and assist as necessary ${ }^{18}$.

Logistics of the trip to Mexico are handled in large part by the students during the preparation phase. Each student is assigned some portion of the details of the trip such as finding hotels, arranging transportation to/from the airport and within Mexico, meals, purchasing thank-you gifts for colleagues, and determining the itinerary for cultural activities. Obviously, many of these tasks require communication and cooperation with the Mexican students.

The class structure allows the students to spend time working together with their Mexican counterparts on their projects. Class time is also devoted to developing a base of Spanish vocabulary common to technical issues in hydrology.

\section{Travel}

The class usually travels to Mexico in the last half of March so there is enough time to develop the projects beforehand and still prepare for final exams afterward. The trip represents 1) a culmination of the work done previously, and 2) a time of discovery as students work face-toface with teammates who speak another language and live within a different set of social, cultural, economic, and political norms.

The trip lasts from 8 to 10 days and this allows students to participate while still having enough time for everything else in their schedules. The relatively short stay in Mexico makes it more affordable to students and doesn't require them to miss summer internship opportunities, or use 
an entire term or semester of study. Allert et al. mentions the advantages of having a short onsite "study-tour" with a one-week frame duration that allows many more students to participate in an international experience. These shorter travel periods are usually available either during spring break or the middle of the semester. These schedules have proven attractive, permitting students

to complete the course and still have time available for summer commitments and employment ${ }^{15}$.

Although the itinerary varies from year to year, the trip is rich with academic and cultural activities. The main academic activities include visits to project sites, project presentations, and group work time. The site visits reveal important weaknesses in the approaches taken to develop the project objectives. Discovering these weaknesses and correcting them is a valuable educational experience as each group learns from its mistakes. Usually the teams will have some time to work together to refine their project after site visits. Important cultural, social, economic, and political differences are revealed as the students often find that their perceived solutions will not work for a variety of reasons.

Presentations are an important part of the experience in Mexico. At UAZ, the collaboration with BYU is fairly well known, so university officials and representatives from interested government agencies often attend the presentations of results at the end of the collaboration. The class usually returns from Mexico with a few weeks remaining in the semester. These weeks are used to finish up the projects and to complete the final report.

\section{MESA and the Global Engineer}

The study abroad program is designed to help students develop the five key attributes, as shown below.

\section{Technical Competence}

The MESA class reinforces fundamental engineering analysis and design principles due to the nature of the class projects. All projects involve developing a water quality, hydrologic, or hydraulic model of an open-ended, real-world problem. During the projects, the basic concepts of modeling are combined with engineering judgment and standard analysis and design procedures within a cultural, social, political environment that differs from their traditional view. This provides an excellent culminating experience to the students' education. For some students, MESA serves as a senior design experience, while for other students, it facilitates their research.

\section{Language}

A big part of MESA's success is due to the large proportion of class members that have command of Spanish and are familiar with Latin cultures. BYU has $25 \%$ of students enrolled in language classes, which is three times the national average ${ }^{14}$. Many of these students have served 2-year service missions to Spanish speaking countries where they have had a significant cultural, although not technical, immersion experience. MESA capitalizes on the rich lingual and cultural background possessed by so many students to provide opportunities to apply those globally enriching experiences to engineering. At least one person with strong Spanish skills is on each team to ensure the ability to communicate with the Mexican students. Group members 
who may not speak Spanish well or at all can still participate and make meaningful contributions as they communicate through their Spanish speaking teammate. Such an arrangement simulates the professional work environment where only one person on a team is able to communicate with foreign clients. The other team members can still contribute their unique knowledge and skills by communicating through the one who speaks the language. This characteristic actually enhances the team building experiences as they recognize (while being forced) the need to rely on their teammates to make the project successful.

\section{Teamwork}

MESA uses teamwork on at least three levels: within project teams, between BYU and Mexican project teams, and among the class as a whole. As described in the preparation phase, each member of the group is expected to contribute in a meaningful way and is held accountable for the assigned tasks in developing the projects. This level of teamwork continues through the preparation and trip phases of the class.

Teamwork between groups is also a big part of the class as the teams from both countries work together both electronically and face-to-face. Additionally, teams with similar projects often exchange ideas and suggestions for their mutual benefit. At this level of teamwork, communication skills become very important as solutions are sought to overcome language and distance barriers. Students learn to communicate efficiently because extraneous words often lead to confusion.

The class as a whole also functions as a team to organize and execute the logistics of the trip. Most of the details of the trip, excluding air travel, are handled by the students. Allowing them to take responsibility for their program increases their sense of ownership and lightens the burden of faculty mentors. Class members are able to practice compromise as they address individual needs and preferences.

\section{Leadership}

In both the preparation and trip phases, the students' leadership is enhanced as their confidence in managing a project, working with others and presenting their results increases. An essential element of MESA is the final report which includes both an oral presentation and written report. Both are completed by the cooperating BYU and Mexican teams in Spanish and English. The combined effect of these projects has been to augment student enthusiasm, confidence and excitement about being civil engineers while improving their cultural, communication, teamwork, and technical skills ${ }^{19}$.

\section{Cultural Sensitivity and Global Awareness}

During the preparation phase, the challenges of working with people from another culture and language become evident as the collaboration proceeds from a distance. During the trip phase, the students are immersed in the culture and can come to understand the origin of the challenges previously discovered as well as have the opportunity to overcome them as they meet their colleagues and spend time with them in social and academic activities. They find that their ideas 
of American-based engineering problem solving often do not work because the historical, cultural, and political landscape is much different. For example, in 2007, one group was assigned to develop solutions to mitigate the flooding in the town of Trancoso Mexico. Trancoso residents report that serious flooding occurs two or three times per year. In recent years, flood waters have reached five feet high in buildings near the engorged stream. After analyzing the situation, the team came up with three solutions. One of the solutions was to deepen and widen the channel so the stream would not flood as frequently. Since existing houses were in the proposed channel, they suggested the government exercise eminent domain and tear down those houses. The American students were quite surprised when told this was impossible because in the past, Mexican governments had forced people to abandon their flooded homes and had even provided them with homes in new areas, but the people sold those homes, moved back to their original dwellings and refused to leave. The American students were forced to rethink their approach.

\section{Assessment}

While much has been published on the need to prepare for globalization, relatively little research has been done on the short term and long term impacts of educational programs designed to teach global engineering skills. Assessment tools are needed to evaluate the effectiveness of current programs and discover what improvements can be made. Even with such an assessment, it is difficult to measure how well students develop non-technical skills, especially subtle outcomes related to cross cultural understanding. During the first years of MESA, anecdotal evidence was gathered that indicated the program was developing global engineering attributes. Though the evidence suggested that MESA was meeting its objectives, there are many factors that can lead to positive feelings about study abroad programs, including solely the opportunity of traveling. Therefore, more formal survey assessment tools were developed to evaluate MESA with results reported in the following sections.

\section{Survey Description}

The initial survey was created after reviewing other surveys used for study abroad programs. One given at Georgia Tech to all study abroad students at the beginning and end of the semester abroad had a particularly large influence on the MESA survey ${ }^{24}$. The main reason for this is that the survey was comprehensive and evaluated many of the same questions that needed to be evaluated in MESA. The modifications made to the Georgia Tech survey were based on the need to focus and assess the five key engineering attributes described previously.

In most questions, respondents are asked to answer on a five-point scale with 5 representing a high or positive response. The different sections of the MESA survey try to measure how well the global engineering attributes were developed in the students. While the survey evaluates more of the engineering attributes defined by Draper ${ }^{9}$ in his comprehensive list, for the purposes of this article the list was consolidated to focus on the five key attributes. The survey also asks the students to rate their reasons for taking the class, to indicate how well the program met its goals, to rate how important these attributes are in their current jobs and to rank the MESA experience relative to other academic experiences. 
Improvements have been made to the survey and it has now evolved to a clearer, more direct tool that assesses only the five key engineering attributes and that provides a more efficient data gathering and analysis.

\section{Survey Results and Discussion}

35 participants from previous years responded to the survey as well as 21 students who participated in the study abroad program of 2008. The trends and results that follow are based on combined data from these respondents.

The survey asks each respondent to rank in order of relevance several reasons why they decided to take the class. The number one reason for taking the class was the opportunity to apply engineering knowledge to real-world problems. Another part of the survey requests that each respondent rank in order of highest expectation to lowest the global engineering skills that he/she expected the class to help develop. Later in the survey, students were asked to rank the same skills in order of most developed to least developed. Comparing the expectation and development scores reveals whether or not the class is meeting the students' expectations. Figure 1 presents the student expectation findings. It indicates that MESA is meeting student expectations. While evaluating the results, it is important to keep in mind that students assessing their own achievement of learning outcomes can be considered as the basic level of program assessment. As discussed further, other assessment tools are needed to support these preliminary findings. The lowest expected and developed skill was for learning Spanish in the engineering profession. Usually about 40 percent of the students do not speak any Spanish because it is not a program requirement. Therefore, those people were put in groups with others who do speak Spanish. This enabled those who did not speak Spanish to contribute and communicate with their Mexican teammates without having to learn the language and might explain why learning Spanish had a much lower score than the other goals. In future surveys this question will be approached differently so that it reflects distinctively the feelings of those who speak Spanish fluently and those who do not. 


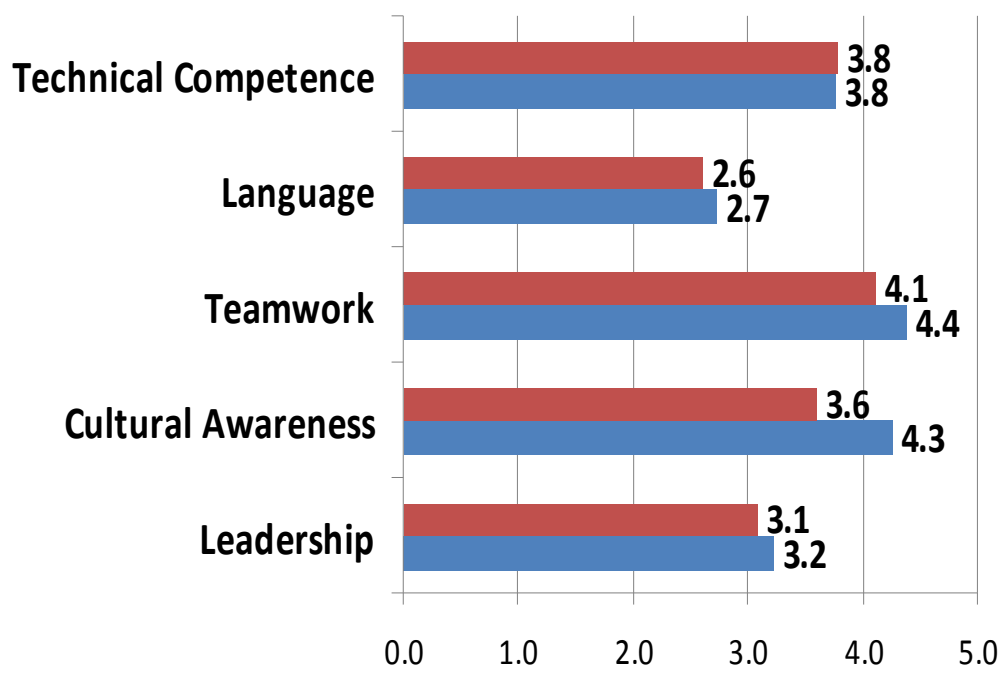

Type of Skill

Development Score

\section{ACTUAL EXPECTED}

Figure 1: Student Perception on Global Engineering Skills Developed by MESA

Sustainability

The objectives to generate research and be cost effective are aimed at producing a sustainable program. An important benefit to the MESA program is that it has continually been a source of new research and thereby has facilitated participating faculty in their research while allowing them to lead students in a rich educational experience. Some of the work from this program has been published in peer-reviewed journals ${ }^{20,21,22,23}$ in Spanish and has formed the basis for Master of Science degree projects. In addition, as more advanced students become involved in interacting with students before they go abroad or once they are there as mentors for those back home, they have helped to reduce the demands on faculty for such "non curricular" support ${ }^{15}$.

\section{Cost-effectiveness}

The average cost of a study abroad program at BYU is $\$ 5000$ while the cost of MESA was $\$ 1,400$ as of 2008 . Further, opportunity cost of internships and time to graduation increase the effective cost of a study abroad; however, MESA is structured in such a way that the 10-day travel in March allows students to still participate in internships and does not delay graduation dates. The 10-day visit constitutes the crowning element for the enlargement of global engineering attributes in students. It is the multi-cultural teamwork and project development during the semester that constitutes the foundation of this study abroad program and aids in the development of such global engineering attributes.

\section{Source of Research}

As mentioned previously, some of the work from this program has been published in peerreviewed journals and has formed the basis for Master of Science degree projects on global 
engineering and water quality model development. Funded research has also been derived from the projects and one Mexican student studying at BYU received a full tuition scholarship and monthly stipend from the Consejo Nacional de Ciencia y Tecnología (CONACYT) to support research growing out of the MESA program.

\section{Conclusion}

The effectiveness of the program derives from the fact that it is sustainable, it is cost-effective to students, it involves ongoing research and it helps develop global engineering attributes (impact in multiple levels). The Mexico Study Abroad Program is a model that could be used in other institutions. The lower language scores from the survey indicate that similar programs may be successful even when not all students possess foreign language skills. As long as one or more team members can effectively communicate in a foreign language the group as a whole can be successful. Further it became apparent that the reliance created on other members fostered a greater sense of teamwork.

When asked for general comments on the class, one student replied, "Every student who goes through BYU who wants this type of experience should be given that opportunity." Further, the survey provides feedback from students suggesting ways in which the program can be improved. Short term and long term assessments are both an important measure of the impact the program has on student preparation in practicing global engineering. There is a benefit to asking students, not only immediately after their experience when they remember vividly the impact of the program, but in years after their experience as well, when they have been in the work place, because they have a more realistic perspective on the program's effectiveness in developing global engineering attributes. Nevertheless, more evidence is needed to corroborate survey findings and steps are being taken in that direction.

\section{Future Work}

From our experience with the MESA program so far we understand that a very important part of the assessment of the program is data gathering in order to perform more complete statistical analyses and draw reliable conclusions. The short term focus of the program may be in product assessment, this is, find a way to evaluate student work and measure the impact the projects are having on the students and the community they benefit. Further, organizing the participation of the Mexican students as a credit class and performing satisfaction surveys to Mexican students and professors may give the overall program more stability.

On the long term there is a need to measure if there are any differences in career outcomes between students that participated in MESA and other students, by gathering data such as job offer upon graduation and career progression, in order to determine the kind of impact the study abroad program had on its participants.

\section{References}

1. F. Hernaut and D. Theis, Research and Engineering Education in a Global Society. Available from: http://w4.siemens.de/FuI/en/archiv/ zeitschrift/ heft1_98/artikel08/index.html. 
2. [Online] May 2007. Available from: http://www.globalization101.org/What is Globalization.html [cited May 14 2:45 pm]

3. T. Hedberg, The Role of the Global Engineer: A European view. In D. Weichert, B. Rauhut, and R. Schmidt, editors, Educating the Engineer for the 21st Century. Proceedings of the 3rd Workshop on Global Engineering Education, New York, Boston, Dordrecht, London, Moscow, 2004. Kluwer Academic Publishers. Available from: http://site.ebrary.com/lib/byuprovo/Doc?id=10067355.

4. R. C. Jones and B. S. Oberst, Megatrends in Engineering Education Today. In 2005 ASEE Annual Conference and Exposition, Conference Proceedings, ASEE Annual Conference and Exposition, Conference Proceedings, pages 10243-10249, Chantilly, VA 20153, United States, 2005. American Society for Engineering Education, American Society for Engineering Education. Available from: http://www.worldexpertise.com/ Megatrends in Engineering Education Today.htm.

5. M. G. Institute, The Emerging Global Labor Market: Part i - The Demand for Offshore Talent in Services. Technical Report Ch. 1, McKinsey Global Institute, June 2005. Available from: http://www.mckinsey.com/mgi/reports/pdfs/ emerginggloballabormarket/part1/MGI demand synthesis.pdf.

6. J. Rajgopal, K. L. Needy, and J. D. Porter, Combining International Experience and Industrial Relevance in a Capstone Engineering Design Course. In Proceedings of the 1997 27th Annual Conference on Frontiers in Education, pages 827-831, Piscataway, NJ, 1997. IEEE. Available from: http://fie.engrng.pitt.edu/fie97/papers/1158.pdf.

7. C Del Vitto. (2008). Cross-Cultural "Soft Skills" and the Global Engineer: Corporate Best Practices and Trainer Methodologies . Online Journal for Global Engineering Education. 1, (3), 1-11.

8. N. A. of Engineering of The National Academies. The Engineer of 2020: Visions of Engineering in the New Century. Technical Report, National Academy of Engineering of The National Academies, 500 Fifth Street, N.W. Washington, DC 20001, 2004

9. J. B. Draper. (2007). Mexico Study Abroad: Assessing the Effectiveness of International Experiences in Teaching Global Engineering Skills. Available from http://contentdm.lib.byu.edu/ ETD/image/etd2184.pdf

10. U. Ravaioli, Eng 199 i, International Dimensions of Engineering [online]. July 2007. Available from: http://www.engr.uiuc.edu/international/eng199/

index.htm [cited July 30].

11. http://www.newsweekshowcase.com/distance-learning/glossary.php?letter=s

12. A. R. Parkinson. (2007). Engineering Study Abroad Programs: Formats, Challenges, Best Practices. Online Journal for Global Engineering Education. 2, (2), 1-17.

13. Institute of International Education, "Open Doors" Database, $<$ http://opendoors.iienetwork.org/?p=131559 >, visited Jan 2009

14. M. Sue Bergin, BYU Magazine, Winter 2002, http://magazine.byu.edu/g/?act=view\&a=845

15. Allert et al. (2007). Making the Case for Global Engineering: Building Foreign Language Collaborations for Designing, Implementing and Assessing Programs, Online Journal for Global Engineering Education. 2, (2), 1-16.

16. [online]June 2007. Available from: http://www.et.byu.edu/news/2007/june/mexico/ [cited July 27, 2007].

17. K. A. Smith and P. Imbrie, Teamwork and Project Management. McGraw Hill, 1221 Avenue of the Americas, New York, NY 10020, third edition, 2007. 
18. International Engineering: Collaboration on hydrologic modeling applications in central Mexico. Available from: http://www.et.byu.edu/groups/ cemexico/.

19. J. Draper, Mexico study abroad: The highlight of an Academic Career. Extraction of why the Mexico study abroad class was the highlight of students' academic careers, August 2007. Available from:

http://www.et.byu.edu/groups/cemexico/research/highlights.htm.

20. Gaytan, Roberto, Jose de Anda, and E. James Nelson, "Computation of the Changes in the Runoff Regiment of Lake Santa Ana Watershed (Zacatecas,Mexico)," International Journal of Lakes and Reservoirs: Research and Management, 2008.

21. Dzul Garcia, Oscar A., E. J. Nelson, E. P. Nunez Pena, F. A. Ortiz Robles, M.E. Kennard, and R. Gaytan Bautista, "Cooperación Universitaria entre UAZ-Brigham Young University: Modelacion Computacional, Uso y Conservación de los Recursos Hidraulicos en el Estado de Zacatecas," Jornada de Investigación de Zacatecas, Noviembre 2005.

22. Ortiz Robles, Fidel A., B. Rodríguez Gonzalez, O. A. Dzul García, E.J. Nelson, E. P. Nunez Pena, and J. A. Fermat Parga, "Modelación Hidrológica Espacialmente Distribuida de la Microcuenca de Trancoso, Zac.," Jornada de Investigación de Zacatecas, Noviembre 2005.

23. Vargas, Ximena, and E. James Nelson, "Usando el Modelo de Sistemas de Cuencas en Estudios PrecipitaciónEscorrentía en colaboración entre Universidades," XXI Congreso Latinoamericano de Hidráulica, IAHR, Octubre, 2004, Sao Pedro, Brasil.

24. G. I. of Technology. Evaluation Survey, Georgia Tech Study Abroad Semester Programs. 